\title{
VOLUNTARISMO FRANCÊS, IDEALISMO E PRAGMATISMO: UMA CONTRAPOSIÇÃO ENTRE AS NARRATIVAS DE RICHARD RORTY E SUSAN STEBBING
}

\author{
HILTON LEAL DA CRUZ1
}

RESUMO: O Presente artigo pretende comparar alguns aspectos da narrativa que a filósofa Susan Stebbing (1885-1943) desenvolve em seu livro Pragmatism And French Voluntarism (1914) com algumas descrições do idealismo alemão desenvolvidas pelo filósofo americano Richard Rorty (1931-2007). Um dos motivos para realizar esse trabalho, sobretudo experimental, de comparar as leituras de dois filósofos sobre tradições filosóficas diferentes, são as evidentes semelhanças que o idealismo alemão apresenta com o voluntarismo francês e as afinidades - bem como divergências - que essas duas tradições possuem com o pragmatismo americano. Longe de pretender neutralidade, minha leitura consistirá em uma aplicação do historicismo rortyano às posições da Prof ${ }^{a}$ Stebbing. Desse modo, espero oferecer uma chave de leitura alternativa para a compreensão do voluntarismo francês e da proposta dos representantes dessa tradição, inclusive do mais conhecido expoente desta, o filósofo Henri Bergson (1859-1941), em sua relação com a Modernidade. Ao final, o texto também defende que o voluntarismo francês, no que ele tem de aproveitável para nós, filósofos secularistas e antiessencialistas -, pode ser descrito como uma forma de pragmatismo.

PALAVRAS-CHAVE: Idealismo - Voluntarismo - Pragmatismo - Metafilosofia

ABSTRACT: This paper intends to compare some aspects of the narrative that the philosopher Susan Stebbing (1885-1943) develops in his book Pragmatism And French Voluntarism with some descriptions of German idealism developed by the American philosopher Richard Rorty (1931-2007). One of the reasons for this rather experimental work of comparing the readings of two philosophers on different philosophical traditions is the evident similarities that German idealism presents with French voluntarism and the affinities as well as divergences - that these two traditions have with the American pragmatism. Far from seeking neutrality, my reading will consist of an application of rortyan historicism to Professor Stebbing's positions. In this way, I hope to offer an alternative reading key to the understanding of French voluntarism and the proposal of representatives of this tradition, including the best-known exponent of it, the philosopher Henri Bergson (1859-1941), in his relation to Modernity. In the end, the text also argues that French voluntarism in what it has to

\footnotetext{
1 Professor de Filosofia do Instituto Federal da Bahia (IFBA), Valença-BA. Doutor em Filosofia pela Universidade Federal da Bahia (UFBA). E-mail: ahasverus9@hotmail.com.
} 
be useful - for us, secularist and anti-essentialist philosophers - can be described as a form of pragmatism.

KEYWORDS: Idealism - Voluntarism - Pragmatism - Metaphilosophy.

Na introdução de seu livro Pragmatism And French Voluntarism, a professora Susan L. Stebbing começa oferecendo uma interessante descrição do pragmatismo. De acordo com seu entendimento , o pragmatismo teria como uma de suas principais características o seu espírito democrático. O "ódio pela autoridade, a paixão pela igualdade” seriam, nessa leitura, aspectos do "espírito de nosso tempo" que teriam influenciado de modo determinante o pragmatismo. Nada mais correto. Filósofos como William James (1842-1910), John Dewey (1859-1952) e Richard Rorty - notórios pragmatistas - ofereceram descrições muito parecidas acerca da relação entre o pragmatismo e a democracia. Em função de sua vocação democrática, a valorização do "homem comum" seria um dos objetivos do pragmatismo e, por isso mesmo, ele se oporia ao "tecnicismo da linguagem e a grosseria da terminologia da filosofia Alemã".

Em contrapartida, o pragmatismo proporia mais o "reconhecimento de outras atitudes em relação ao universo do que aquela que consiste em tomá-lo como um problema a ser resolvido.” (STEBBING, 1914, p. 02). Além desses primeiros aspectos, o pragmatismo, na leitura de Stebbing, também se caracterizaria como uma filosofia que visa à valorização do sentimento sobre o intelecto, a afirmação dos aspectos volitivos de nossa experiência, partilhando por isso de algumas afinidades com a tradição inaugurada na França pelo pensamento de Mine de Biran (1766 a 1824). Nessa leitura, tanto o pragmatismo quanto o voluntarismo francês procurariam, através de diferentes caminhos, levar o pensamento filosófico a um contato mais estreito com a vida, investindo o pensamento com o "encanto da personalidade" a fim de "soprar vida dentro dos ossos mortos da metafísica". Além disso, tanto um quanto o outro considerariam o intelecto como uma faculdade eminentemente prática, por um lado, enquanto por outro teriam sido levados a "admitir a contingência no reino da ciência física" (Idem, p. 04).

Contudo, segundo a autora, as afinidades terminariam por aí. Enquanto o pragmatismo desenvolve-se como uma filosofia que prima pela valorização da opinião popular, pelos processos públicos de justificação, o voluntarismo francês - ao contrário - parece caracterizar-se pela valorização das experiências "interiores". O pragmatismo, na leitura de 
Stebbing, "quer seja concebido como um tipo de utilitarismo do pior tipo" ou "simplesmente como uma teoria da manipulação de dados para os propósitos da ciência" (STEBBING, Op. Cit. P. 04) tem as suas posições filosóficas determinadas pelo desejo (que a autora parece considerar antifilosófico) de levar a filosofia a "descer" ao nível do homem comum, fazendoa envolver-se com as labutas que constituem a maior parte de nossas vidas. Por outro lado, no voluntarismo francês - aparentemente mais sério e profissional segundo o ponto de vista da autora - a condenação do intelecto é feita em função da "inabilidade deste para resolver as antinomias kantianas e os paradoxos zenonianos".(Idem, Ibid.) Ou seja, enquanto o suposto anti-intelectualismo pragmático teria como fator motivante um impulso anti-filosófico, o voluntarismo francês, embora equivocado em muitas de suas posições, seria genuinamente filosófico e, portanto, digno de um estudo mais atento.

Começarei esse ensaio questionando alguns aspectos da descrição que a autora faz do pragmatismo na introdução de seu livro. Em seguida irei tentar desenvolver um enquadramento alternativo para alguns aspectos da narrativa que ela oferece sobre o voluntarismo francês. No final, espero mostrar que, em tudo que o voluntarismo francês tem de aproveitável e compreensível, ele é um tipo de pragmatismo.

O livro da professora Stebbing foi publicado em 1914 e embora nessa época J. Dewey, um dos mais famosos pragmatistas clássicos, estivesse no auge de seu vigor, é curioso que o seu livro não faça nenhuma menção a ele. O silêncio sobre a obra de Dewey, bem como a consideração do pragmatismo como um tipo de voluntarismo, parece-me particularmente problemáticos para o desenvolvimento do argumento de Stebbing. Ao afirmar que o pragmatismo procura desenvolver uma teoria que vise "satisfazer a nossa natureza emocional e assegurar a satisfação de nossos anseios e aspirações" (STEBBING, 1914, p. 06), ela está, evidentemente, oferecendo um retrato no mínimo ingênuo do pragmatismo, mesmo que seu retrato tenha sido pintado utilizando apenas as tintas oferecidas por Ferdinand Schiller (1864 - 1937) e por William James (1839-1914). Apesar de considerar os recursos do pensamento ou da linguagem - como ferramentas a serviço do bem-estar humano, o pragmatismo não oferece uma compreensão dualista da natureza humana que situa os desejos de um lado e o intelecto do outro. Ao contrário, um dos aspectos centrais do pragmatismo consiste em sua proposta oferecer uma descrição das nossas crenças de modo que possamos compreendê-las sem dividir nossas ações em processos cognitivos e não cognitivos. 
O que James chamava de "método pragmático" - desenvolvido na verdade por C.S.Pierce (1839-1914) - consistia em "tentar interpretar cada noção traçando as suas consequências práticas respectivas.” (JAMES, 1974, p. 44). Ou seja, se de duas noções decorrem as mesmas consequências, logo, pode-se considerá-las a mesma noção. Ao levar em consideração esse aspecto do pragmatismo, Richard Rorty afirma que:

Ele (o pragmatismo) quer ater-se a visão de mundo materialista que tipicamente forma o pano de fundo da consciência liberal contemporânea; e isso enquanto abstêm-se da afirmação de que essa visão tenha sido "estabelecida" por um "método confiável para atingir a verdade sob a natureza das coisas." Se nós apreendermos que o coração do pragmatismo é a sua tentativa de substituir a noção enquanto "representação da natureza das coisas" e, ao invés disso, pensarmos em crenças como regras auspiciosas de ação, então fica fácil recomendar uma atitude experimental e falibilista, mas difícil isolar um método que venha a corporificar essa atitude (RORTY, 1997, p.94).

Do que Rorty afirma no trecho acima, pode-se perceber que, em vez de opor a vontade ao intelecto, o pragmatismo procura oferecer outra compreensão da relação entre os seres humanos e o mundo, uma que nos permita ver nossas ações e ideias do ponto de vista das suas consequências práticas. $\mathrm{O}$ pragmatismo consistiria em uma tentativa de compreender o intelecto, bem como as emoções e os desejos, como respostas comportamentais ao meio que nos cerca, como hábitos ou como disposições para a ação. Sendo assim, penso que, do ponto de vista de um pragmatista como Richard Rorty, o voluntarismo, longe de ser um traço do pragmatismo, seria visto apenas como mais um tipo de "platonismo às avessas", um resultado da

tentativa romântica de enaltecer a carne em relação ao espírito, o coração em relação a mente e uma faculdade mítica chamada vontade em relação a outra faculdade igualmente mítica chamada razão. (RORTY, 2007, P. 73) ${ }^{2}$

A estratégia do pragmatismo para escapar do essencialismo seja de tipo platônico/racionalista, seja de tipo antiplatônico/voluntarista, é adotando uma atitude holista e historicista em relação a tópicos como o conhecimento e a ação. É por esse motivo que, do ponto de vista rortyano (que é em muitos aspectos semelhantes ao de Dewey), os parâmetros para a ação e para o juízo dos indivíduos são parasitários do contexto cultural em que eles nascem. As razões bem como os desejos destes não são independentes das circunstâncias históricas contingentes que levaram ao desenvolvimento do tipo de cultura no interior da qual eles desenvolveram seus modos de agir e pensar. Claro, segundo a narrativa pragmatista, tais culturas se desenvolveram visando oferecer possibilidades mais amplas de felicidade, de

\footnotetext{
${ }^{2}$ Rorty, Richard, A Contingência da Identidade em Contingência, Ironia e Solidariedade, 2007, p.73.
} 
adaptação e sucesso, a partir da reação às adversidades e problemas oferecidos pelas circunstâncias.

Reconhecer que nossos valores e crenças se desenvolvem a partir da reação a problemas concretos não é o mesmo que dizer que o pragmatismo "reconhece os direitos da emoção como um fator determinante da verdade". (STEBBING, 1914, p.06) Considerando que, para pragmatistas como Rorty e Dewey, o que conta para nós como verdade sempre está associado a determinados parâmetros culturais, não é razoável afirmar que a vontade seja esse parâmetro. A leitura que a porfessora Stebbing faz do pragmatismo me parece não levar em consideração o aspecto historicista dessa tradição nem considerar a sua proposta de tentar conciliar aspectos diferentes do pensamento moderno em uma atitude ao mesmo tempo materialista e idealista (ou empirista e racionalista). Por outro lado, é preciso dar a mão à palmatória e reconhecer que, em ensaios como o célebre (e polêmico) $O$ Desejo de Acreditar (ano), James parece sugerir que aquilo que tomamos como verdadeiro depende apenas de nossa vontade. Nesse ensaio, como afirma Rorty, James

aceita exatamente o que ele deveria rejeitar: a ideia de que a mente está dividida precisamente pelo meio em intelecto e paixão, e a ideia de que possíveis tópicos de discussão estão divididos precisamente entre cognitivos e não cognitivos. (RORTY, 1999, p.155)

Em vez de optar por essa estratégia, alega Rorty, James poderia ter preferido, como fez em outros ensaios, substituir a dicotomia cognitivo versus não cognitivo pela separação entre crenças úteis para propósitos coletivos e crenças úteis para propósitos pessoais. Nesse caso, o direito de sustentar certas convicções sem apresentar evidências aos nossos pares não se basearia nas "exigências do coração", e sim no fato de que tais convicções não afetam a vida de outras pessoas. Mas nesse ensaio específico, James não argumenta nesse sentido e, aparentemente, Stebbing explora esse "deslize" dele, além de outras afirmações soltas de Schiller ${ }^{3}$, para estabelecer um juízo generalizante sobre o pragmatismo.

Contudo, tomar um ensaio de James, e algumas observações esparsas de Schiller, deixando de considerar outros aspectos e autores que foram cruciais para o pragmatismo, não me parece o procedimento narrativo mais aconselhável. O resultado da narrativa obtida

\footnotetext{
${ }^{3}$ Schiller, aliás, assume em muitos assuntos algumas posições muito distantes das posições de Pierce, James, Dewey e Rorty. Tanto a defesa da eugenia, com todos os sentimentos antidemocráticos que a acompanham, quanto o humanismo de Schiller (que ele mesmo fez questão de diferenciar do sentido estritamente metodológico do termo pragmatismo) fazem de Schiller um pragmatista atípico. As "semelhanças de família" que fazem dele Schiller um pragmatista de fato existem, mas me parece que Stebbing vai procurá-las no lugar errado.
} 
através desse procedimento também não me parece o mais interessante. Sob o olhar da professora Stebbing, o pragmatismo parece ter como centro de suas inquietações o problema da verdade e a necessidade de defini-la de um modo anti-intelectualista e voluntarista. Nada mais equivocado. O pragmatismo, ao contrário, deveria ser descrito - com as devidas ressalvas - como uma tradição empenhada em renovar a própria autoimagem da filosofia, tida até então como uma atividade "investigativa"; por isso mesmo o pragmatismo é uma tradição antiepistemológica. Nesse sentido, a crítica cultural - para usar uma expressão rortyana seria a principal ocupação dos filósofos pragmatistas.

No texto que segue, tentarei oferecer uma descrição pragmatista do texto da professora Stebbing. Farei isso tentando encaixar alguns aspectos da narrativa que ela oferece a respeito do voluntarismo francês no interior da narrativa rortyana da modernidade para, a partir desse encaixe, avaliar alguns méritos e deméritos dessa tradição para uma crítica da cultura moderna.

\section{Voluntarismo Francês}

O voluntarismo Francês, segundo Stebbing, nasce e se desenvolve como uma reação, por um lado, ao racionalismo e, por outro, ao materialismo característico dos séculos XVII e XVIII. Segundo ela, a resposta ao materialismo/racionalismo francês seria o surgimento de uma tradição voluntarista, que situaria a vontade como um aspecto mais fundamental que o intelecto, tomando-a "metafisicamente, como a natureza última da realidade." (STEBBING, 1914, p. 13). O voluntarismo Francês não é a única tradição a reagir desse modo ao racionalismo de tipo cartesiano, bem como ao "sensacionismo" estritamente materialista. Parece-me que o idealismo alemão, tal qual ele foi descrito pelo historiador das ideias Isaiah Berlin (1909 - 1997), guarda muitas afinidades com a descrição do Voluntarismo Francês oferecida pela professora Stebbing. Segundo Berlin, o idealismo alemão teria como alguns de seus traços principais a valorização da particularidade contra o universalismo, da vontade contra o pensamento e, mais importante, da ação contra a contemplação. Ambos, idealismo alemão e Voluntarismo Francês, são movimentos "reativos", que opõem os aspectos mais "subjetivos", pessoais, de nossa experiência contra o empenho racionalista em estabelecer certezas baseadas em dados objetivos, acessíveis a qualquer pessoa. No sentido de tornar essa afinidade mais palatável, comparemos, por exemplo, um determinado aspecto da concepção 
de eu desenvolvida por dois dos principais representantes de ambas as tradições: J. G. Fichte (1762-1814), pelo lado do idealismo alemão, e Maine de Biran (1766-1824), pelo lado do voluntarismo francês. Referindo-se a Fichte, Isaiah Berlin acentua que para este "é o impacto sobre mim do que é externo a mim e o esforço para resistir a esse impacto que me permitem saber que sou o que sou." Berlin conclui que, para os idealistas e românticos:

Descartes e Locke estão evidentemente equivocados - a mente não é uma lousa sobre a qual a natureza grava o que lhe agrada; não é um objeto, mas uma atividade perpétua que modela seu mundo para reagir às suas demandas éticas. É a necessidade de agir que gera a consciência do mundo real. (BERLIN, P. 574, 2002)

Ora, do mesmo modo, para o pai do voluntarismo francês, o filósofo Mine de Biran, a consciência existe apenas como esforço oposto à resistência do objeto externo - a autoconsciência seria o resultado da resistência imposta pelo mundo circundante. A noção de vontade - ou esforço - é entendida por Mine de Biran como o elemento fundamental que dá origem a própria auto-consciência " $\mathrm{O}$ eu identifica a si mesmo completamente com essa força atuante" (STEBBING, 1914, p.19) Para ambos os filósofos, Fichte e Mine de Biran, o eu e o não eu colocam-se um perante o outro em uma relação de contínua oposição. Tal compreensão agonista da relação indivíduo-mundo gera uma compreensão voluntarista da individualidade. Por outro lado, tal compreensão, em seus desdobramentos lógicos e históricos, ao tentar justificar-se como uma descoberta dos "fundamentos do real", termina desaguando em um tipo de "idealismo"4 (embora Stebbing evite usar esse termo).

Um elemento parece faltar à narrativa sobre o voluntarismo francês desenvolvida pela prof ${ }^{a}$ Stebbing. Esse elemento, penso, seria uma descrição mais direta do tipo de problema técnico ou teórico que o voluntarismo francês via no materialismo e no racionalismo. No decorrer de sua narrativa, Stebbing afirma que o voluntarismo francês partia da afirmação de que o intelecto "falhou em resolver os problemas que a metafísica oferece" e que por isso mesmo os voluntaristas "procuram outros meios diferentes do intelecto para a sua solução" (STEBBING, 1914, p161). Contudo, posso estar equivocado, mas não me parece que a professora tenha apresentado nenhum exemplo de um desses problemas não solucionados do racionalismo. ${ }^{5}$ Não fica claro também porque ela acha que filósofos como Condilac e Descartes estavam realmente empenhados em resolver tais problemas e não em propor uma imagem completamente diferente do ser humano. Essas dúvidas me levam a sugerir que, ao

\footnotetext{
${ }^{4}$ Entendo por idealismo a tese segundo a qual a realidade é "produzida pela atividade do eu".

${ }^{5} \mathrm{Nem}$ dos motivos pelos quais não podemos simplesmente abandoná-los, dar de ombros a todos eles.
} 
invés de vermos o voluntarismo como um continuador da metafísica clássica, ele deveria ser visto como uma mal sucedida tentativa de rompimento com essa tradição.

O idealismo Alemão, pelo menos em sua origem, parece-me consistir em uma tentativa de dar uma explicação acerca da relação pensamento-matéria que evitasse o problema do ceticismo. Portanto, o idealismo alemão inicia seu desenvolvimento a partir do ponto em que Immanuel Kant transforma a discussão científica sobre a relação entre sensações e ideias em uma pergunta sobre o que torna possível a própria ciência. Segundo Rorty, "o idealismo parte de um problema científico não resolvido - a natureza do conhecimento - transmutando-a numa pergunta sobre a possibilidade do conhecimento." (RORTY, 1982, p. 214). O idealismo, segundo essa leitura, teria parecido importante por seu aparente mérito em conseguir dar uma resposta a um problema científico submetendo a própria possibilidade da ciência a um tipo de atividade "transcendental" que caberia à filosofia estudar. A partir dessa leitura, conclui Rorty, o idealismo passa, de uma resposta a um problema supostamente científico, para uma protesto contra a irrelevância da filosofia para o resto da cultura moderna.

O voluntarismo francês, por outro lado, não começa como uma tentativa de dar uma resposta a um problema científico. Aquilo que a professora Stebbing chama de "método introspectivo" inaugurado por Mine de Biran não parece se desenvolver como uma resposta para um problema científico. A busca por "um ponto de vista mais íntimo do que aquele adotado pela filosofia de Condilac" - tomando por base o que nos relata Stebbing - não me parece ter sido motivada pela compreensão de qualquer problema oriundo do estado de desenvolvimento da ciência no século XIX, como, por exemplo, o problema da relação mente versus matéria. O ponto de partida da reflexão voluntarista não foi um problema oriundo do estado de desenvolvimento das ciências ou da política no século XIX. O que parece é que Mine de Biran toma como fato inquestionável a ideia de um espaço interno, que segundo Rorty teria sido inventada por Descartes e levada a sério pelos empiristas, que havia sido deixada de lado pelos sensacionistas. O assim chamado "método introspectivo" de Mine de Biran, entretanto, não me parece conectado com qualquer preocupação de ordem epistemológica, muito menos com o método das ciências da natureza.

Como não consigo conectar dialeticamente o voluntarismo francês com os problemas da ciência, só posso compreender as razões para o seu surgimento e desenvolvimento relacionando-o à relativa perda de prestígio sofrida pela filosofia e pela religião com o 
desenvolvimento das ciências positivas. Ou seja, penso que seria razoável afirmar que o voluntarismo francês caracteriza-se apenas como um protesto contra a irrelevância da filosofia para o resto da cultura. Esse protesto articula-se através do desenvolvimento de uma compreensão de nossa identidade moral que não é nem científica nem religiosa. Desse modo, enquanto os cientistas e racionalistas lidavam com aspectos de nossa natureza que eram "meramente instintivos", "materiais", "mensuráveis" ou "analisáveis", envolvidos com os processos de sobrevivência, os voluntaristas, ao contrário, estavam pesquisando "a nossa essência", aquela parte de nosso que ser que nos faz humanos.

Depois de Kant, o idealismo alemão desenvolveu-se na mesma direção do voluntarismo francês. Contudo, o problema da verdade e do modo como podemos nos assegurar de possuí-la estava nas origens kantianas do idealismo alemão, mas não na origem e nem no resultado, acredito - do voluntarismo francês. Eu me arriscaria até a afirmar que, tomando por base a narrativa da professora Stebbing, as questões de ordem epistemológica sobre como evitar o ceticismo, como os dados particulares podem ser universalizados etc. nunca estiveram no centro das preocupações de pensadores da tradição da qual faz parte, por exemplo, Henri Bérgson.

Aliás, sendo mais específico, o que o voluntarismo francês parece tomar como sendo "o problema da verdade" não me parece conectado com questões relativas à tentativa de estabelecer critérios para separar a verdade do erro. Pelo contrário, propostas como a Mine de Biran, que consiste em identificar a verdade com algo chamado "ação profunda" ou com a "vida do espírito" - termos que indicam uma suposta vivência não discursiva -, deixam-nos sem nenhum critério para realizar o tipo de trabalho que geralmente se espera que a epistemologia realize (STEBBING, 1914, p 63-64). Sendo mais específico, o que os voluntaristas franceses chamam de "o problema da verdade" é algo tão diferente daquilo que preocupava os empiristas e idealistas kantianos que, aparentemente, assemelha-se com algo diferente de um problema epistêmico.

A questão de saber o que somos, qual nossa essência, e em que nos diferenciamos, tanto da matéria bruta quanto dos animais, parece-me ser a principal preocupação do voluntarismo francês. É por esse motivo que Stebbing acusa Mine de Biran de manter sua reflexão em um nível "ideológico e não propriamente genético" ao afirmar que "a consciência do esforço é o fato primário da consciência", afirmação essa que pressuporia "alguma concepção rudimentar do eu e do não-eu, ao qual o primeiro opõe resistência.” (STEBBING, 
1914, p. 19). De fato, se Stebbing estiver correta ao afirmar que a filosofia de Mine de Biran "se mantêm em um nível meramente ideológico", penso que essa é a sua principal virtude.

A concepção voluntarista e agonista do eu oferecida por Mine de Biran - em minha opinião muito semelhante àquela desenvolvida por Fichte, Stirner, Nietzsche e Freud - alinhase com todo um movimento pluralista romântico de dessacralização da identidade que teve lugar no século XIX. Tal movimento, seguindo os caminhos abertos pela revolução francesa, caracterizou-se pela tentativa de articular uma compreensão mais autônoma e ativa da identidade humana.

A afirmação kantiana de que o indivíduo "esclarecido" é aquele que se torna "senhor de si" seria, nessa leitura, traduzida por esses "filósofos do eu" como um apelo à agência humana, em oposição a uma atitude passiva ou resignada diante do mundo, como aquela recomendada pelo cristianismo. Indo além, essa agência terminou sendo vista como responsável pela própria consciência de si, pela própria autocriação, abrindo caminho para movimentos como o existencialismo e o neopragmatismo rortyano. Filósofos como Mine de Biran estavam procurando, penso, abrir espaço para uma compreensão do eu como agente moral que pudesse ser harmonizada, por um lado, com a cultura pluralista que estava emergindo e, por outro lado, com o tipo de mecanicismo que a física newtoniana havia desenvolvido. Mais importante: não é através da argumentação, da consideração dos prós e contras de teses rivais que tais pensadores fizeram isso. O assim chamado "método introspectivo" de Mine de Biran, pelo que entendi, parece assemelhar-se mais com o trabalho de escritores como Proust ou Dostoievski do que com o de David Hume ou Kant. Uma autoanálise é tudo que Mine de Biran nos oferece como suporte para sua descrição do eu, e ao contrário da professora Stebbing, não vejo isso como algo ruim. Mas, infelizmente, a importante tentativa desenvolvida por Mine de Biran, que procurava fazer da "espontaneidade individual e da perfeição privada" os paradigmas da auto-realização humana, foi conjugada, sobretudo no período posterior do voluntarismo Francês, com uma atitude essencialista e anticientífica que desaguou no misticismo de autores como Bergson. Se tudo que disse acima possui alguma coerência, penso que poderíamos compreender o voluntarismo francês que a professora Stebbing descreve se articulando a partir das seguintes demandas:

1- Fazer da filosofia um campo de estudos mais fundamental, universal e evidente que a ciência.

2- Oferecer uma descrição do intelecto que o naturaliza e o concebe de modo pragmático. 
3- Descrever a nossa identidade de modo que a ação seja vista, de algum modo, como mais importante que a contemplação para a definição do que nos torna humanos.

Do modo como eu vejo, o trabalho de Mine de Biran, bem como o dos pensadores pragmatistas, tem como principal objetivo atender aos pontos 2 e 3 da lista acima. Susan Stebbing acusa Mine de Biran de "não separar claramente cognição de vontade" além de fracassar ao tentar "explicar a universalidade e a necessidade das categorias deduzidas" (STEBBING, ano, 1914 p. 21 ) a partir de sua análise introspectiva. No meu entendimento, tais problemas no pensamento de Mine de Biran apontam para o fato de que ele não estava preocupado com o item 1 da lista oferecida acima, preferindo gastar sua energia ao tentar articular 2 e 3. Contudo, a partir do trabalho do filósofo Félix Ravaisson-Mollien (18131900), as coisas mudam no voluntarismo francês. A partir desse ponto, os continuadores dessa tradição concentram suas energias na tentativa de "fundamentar" os pontos 2 e 3 através de diferentes modos de articular o ponto 1. Isso é feito através da subordinação de uma descrição voluntarista da identidade humana à variadas formas de essencialismo de inclinação idealista.

Na filosofia de Félix Ravaisson, por exemplo, podemos perceber a filosofia do eu desenvolvida por Mine de Biran tomar a direção "de um dinamismo espiritualista que reconhece a matéria apenas como se ela fosse uma sombra da existência." (STEBBING, 1914, p. 24) Em Ravaisson, a compreensão voluntarista do eu é sustentada a partir de um tipo de panteísmo muito semelhante ao de Schelling (de quem, aliás, ele assistiu as aulas em Munich durante o ano de 1836). Um dos aspectos centrais da filosofia de Ravaisson, assim como do idealismo alemão, consiste em tentar encontrar algum tipo de continuidade entre espírito e natureza através de um certo tipo de panteísmo. Eu arriscaria dizer que, assim como o pragmatismo e o hegelianismo, o voluntarismo francês a partir de Ravaisson segue tentando desenvolver uma postura antidualista.

$\mathrm{O}$ antidualismo do voluntarismo francês, segundo a professora Stebbing, consistiria em uma atitude que pretende explicar as coisas inertes por referência aos processos vitais que caracterizam a vontade humana. ${ }^{6}$ A pretensão final desse antidualismo seria "reconciliar em uma harmonia sensível para o coração termos talvez inconciliáveis para a inteligência." (STEBBING, 1914, p.24) Contudo, ao contrário tanto do pragmatismo quanto do

\footnotetext{
${ }^{6}$ É no fenômeno do hábito que Ravaisson procurou reconciliar a existência da matéria com o espírito. Para Ravaisson, "No fenômeno do hábito nós vemos a vontade se tornando automatismo" e a própria natureza não seria outra coisa senão "uma vontade adormecida". Portanto, ao desenvolvermos hábitos nossa vontade estaria se degradando no mesmo tipo de mecanicismo que caracteriza os processos naturais. (RAVAISSON apud STEBBING, 1914, p. 25)
} 
hegelianismo, o voluntarismo de Ravaisson não assume a cultura e a história como um elemento mediador da relação entre matéria e espírito. Ao contrário, parece-me que uma das características do pensamento francês, de Ravaisson à Bergson - característica responsável pelo tipo de "misticismo" no qual essa tradição me parece desaguar - é a tentativa de estabelecer essa continuidade a partir da análise de algum suposto dado imediato da experiência.

A ideia de uma faculdade chamada "intuição" - pelo menos em Bergson - cumpriria o papel de instância onde se daria o contato com tais "dados imediatos". Ou seja, o voluntarismo francês parece utilizar o vocabulário empirista ao falar em "dados imediatos", mas aborda esses dados pelo seu aspecto "interno". Ao adotar essa estratégia, ele rejeita a metafísica realista que, geralmente, serve para salvar os empiristas da acusação de solipsismo. Contudo, nessa minha narrativa alternativa, eu vejo o voluntarismo francês, na filosofia de Bergson, desaguando em um tipo de "intuicionismo" cujas consequências solipsistas me parecem inevitáveis.

O pensamento conceitual, comunicável, é acusado por Bergson de atingir apenas "pontos de vista parciais", uma vez que estão intimamente determinados "pelas exigências da vida prática" (BERGSON Apud. STEBBING, 1914, p. 46) Em contrapartida, a faculdade chamada "intuição", que lidaria com experiências incomunicáveis, é considerada por Bergson como "a faculdade filosófica por excelência, pois somente ela seria competente para atingir a verdade". (Idem, p.131) O primeiro problema que decorre dessa formulação é de ordem metodológica: como Bergson procedeu para desenvolver sua posição filosófica? Através da intuição ou do intelecto? Sendo o pensamento conceitual acusado de falsificar a realidade, e sendo incomunicável a experiência direta obtida através da intuição, não se poderia elaborar um sistema filosófico com pretensões representacionistas através de nenhum dos dois. Logo, parece-me que, para explicar como conseguiu desenvolver seu sistema filosófico, Bergson precisaria ter formulado uma terceira faculdade, diferente da intuição e do intelecto. ${ }^{7}$ Mas ele não faz isso. Problemas semelhantes no voluntarismo francês não passam despercebidos pelo olhar da professora Stebbing. Ela fala, por exemplo, de um dualismo decorrente da oposição entre intelecto e intuição. Tal dualismo teria como consequência uma radical distinção entre

dois tipos de vida: uma baixa e adaptada a uma realidade distorcida, uma vez que a realidade em si mesma é adaptada apenas a vida elevada, espiritual, enquanto uma é atingida pelo intelecto atingimos a outra através da intuição. (STEBBING, 1914, p. 137)

\footnotetext{
${ }^{7}$ Esse seria, no meu entendimento, mais um motivo para ver o voluntarismo como uma ruptura com o vocabulário da tradição metafísica. Se olharmos por esse ângulo, poderíamos ver o voluntarismo e o pragmatismo como tentativas poéticas de modificar nosso vocabulário moral através do uso metáforas.
} 
Essa mesma distinção, admite a autora, "constitui um irreconciliável conflito entre os dois eus", (STEBBING, 1914, p. 141) embora Bergson reconheça que ambos tem como origem o mesmo "impulso vital", isso não resolve o problema. Ou seja, o voluntarismo francês fracassa em realizar um de seus mais compreensíveis objetivos: superar o dualismo, pois seus resultados conduzem a uma outra dicotomia ainda mais radical que a oposição entre a Res Extensa e a Res Pensante cartesiana. Além do mais, tal distinção conduz ao problema de estabelecer exatamente em que sentido a faculdade que Bergson chama de intuição garante uma "apreensão mais verdadeira" ${ }^{8}$ da realidade. Ao afirmar que os "conceitos negam o real, pois o manipulam em função dos interesses da ação", (Idem, p. 143) Bergson perde qualquer possibilidade de dizer algo de mais específico sobre o que ele chama de intuição. Ou seja, a filosofia de Bergson parece ter como resultado uma tentativa de "expressar o inexprimível" resultando, portanto, em um tipo de misticismo. ${ }^{9} \mathrm{O}$ idealismo alemão obteve resultados parecidos a partir da mesma tentativa de abrir espaço para uma compreensão do eu como agente moral em um mundo pós-religioso. No caso do idealismo alemão, vemos Kant falando intuições que são sintetizadas a partir da atividade de um suposto eu transcendental. Mas, como observa Rorty,

na medida em que a intuição kantiana é exprimível, ela é apenas um juízo perceptual (submetido a conceitos), e portanto não é meramente "intuitiva". Na medida em que é inexprimível, é incapaz de desempenhar função explicativa. (RORTY, 1982, p. 56)

Penso que tal apelo a aspectos não discursivos de nossa experiência é crucial tanto para o idealismo alemão quanto para o voluntarismo francês. Em ambas as tradições, recorrer ao inefável, parece-me, é um modo de tentar retirar a filosofia do espaço público, fazendo dela um assunto eminentemente privado, voltado para a autocriação. Claro, esse apelo ao inefável não seria necessário se todos os idealistas e voluntaristas franceses estivessem satisfeitos com o tipo de materialismo característico da cultura de seu tempo, ou tivessem nascido em uma sociedade que impõe um único modelo de autorrealização moral. A reatividade em relação á própria cultura e a ausência de um modelo único que dê voz a essa reatividade são pré-requisitos para a demanda romântica por autocriação que, creio, é possível identificar no voluntarismo, no idealismo e no pragmatismo ${ }^{10}$. Desses três, no entanto, parece

\footnotetext{
${ }^{8}$ Esse é o tipo de uso de uma expressão oriunda de um vocabulário platônico que, penso, complica a situação dos voluntaristas e idealistas.

9 A maior crítica da autora com relação ao pragmatismo é o fato dele ser "antifilosófico", contudo, caberia questionar se o misticismo decorrente das posições de Bergson - que ela respeita mais do que qualquer pragmatista - é menos antifilosófico do que o naturalismo pragmático.

${ }^{10}$ Foi Nietzsche que nos legou a ideia de que a reatividade é um traço característico de toda formulação moral (ou pelo menos de toda moral pós-cristã).
} 
que o pragmatismo é o único que desenvolve uma ideia de autocriação reativa sem apelar a qualquer suposta instância inefável de nossa experiência. Partindo de uma crítica ao próprio projeto fundacionista kantiano, o pragmatismo oferece uma compreensão alternativa do processo de autocriação que, embora romantizada, não reivindica ter descoberto "nossa verdadeira essência."

O trabalho de Richard Rorty poderia ser visto como um exemplo dessa proposta. O livro Contingência Ironia e Solidariedade (2007) propõe-se a levar adiante o trabalho de elaborar uma nova compreensão de nossa identidade sem, no entanto, incidir nos erros do voluntarismo que apontei acima. No segundo capítulo da obra citada, o pragmatista americano desenvolve a proposta de uma compreensão contingencialista da individualidade. Essa proposta se articula através de uma ampla reinterpretação do trabalho de filósofos como Hegel, Nietzsche, Freud e Donald Davidson. Para Rorty “os filósofos importantes do século XX são aqueles que tentaram dar continuidade aos poetas românticos, rompendo com Platão e vendo a liberdade como reconhecimento da contingência." (RORTY, 2007, p. 61) Tal reconhecimento passaria pela substituição da figura do cientista pela do poeta como herói paradigmático da humanidade. Todos esses pensadores ${ }^{11}$ estariam tentando evitar "qualquer coisa que cheire à filosofia como comtemplação, como tentativa de ver a vida uniformemente e vê-la inteira, para insistir na pura contingência da existência individual"

A proposta filosófica de Rorty visaria, por um lado, oferecer uma versão mais modesta de uma concepção romantizada do eu, e por outro lado, evitar as acusações que levantei acima contra o voluntarismo. A primeira meta é atingida por Rorty através da articulação de uma compreensão do eu como uma "trama de crenças". Ou seja, para Rorty, aquilo que nos torna humanos é apenas a capacidade utilizar linguagens, assim como o que nos torna indivíduos é a capacidade de utilizar certas expressões e frases de um modo diferente criando assim metáforas (Idem, p.78). O desenvolvimento das metáforas, a redescrição de certos eventos através de um uso novo das palavras, estaria associado à necessidade de lidar como eventos particulares, com traumas, por exemplo. A metáfora, assim como a linguagem, possuiria, portanto, um caráter instrumental. Ao compreender essa mesma descrição do eu como proveitosa e útil para uma cultura pluralista como a nossa, e não como um fato sobre nossa essência volitiva, Rorty (2007) espera ter se esquivado das críticas que geralmente são voltadas contra o voluntarismo e contra o idealismo. Para obter ambos os resultados,

\footnotetext{
${ }^{11}$ Penso que Rorty ficaria feliz em incluir (através do mesmo tipo de leitura seletiva que ele que faz de Nietzsche) os voluntaristas franceses nesse grupo de precursores.
} 
entretanto, Rorty propõe um rompimento radical - para muitos radical demais - com a tradição filosófica.

Essa inclinação antiautoritária do pragmatismo, que Rorty pretende levar às últimas consequências, talvez seja o principal motivo do desprezo de Stebbing, bem como de muitos outros filósofos, pelo pragmatismo. Filósofos como James, Dewey e Rorty escreveram muitos de seus textos visando naturalizar nossa autoimagem, enquanto a tradição platônico-kantiana parece ter como um de seus principais objetivos resistir a essa naturalização. A professora Stebbing parece se aproximar estreitamente do racionalismo ao fazer afirmações como: "as antinomias que eles - os pragmatistas - pretendem resolver são antinomias da razão, então elas deveriam ser resolvidas pela razão. (STEBBING, 1914, p.162). Ora, é claro que a própria ideia do que é racionalidade é objeto de ampla controvérsia e Stebbing não nos ajuda a compreender como ela interpreta essa noção. Eu apostaria na hipótese de que a autora entenda por racionalidade algum tipo de "essência humana", uma suposta faculdade que nos coloca diante de questões cujo valor está nelas mesmas e não em algum resultado prático que possa decorrer de seu enfrentamento. Esse essencialismo, penso, é que leva a autora a levantar afirmações como a seguinte:

A suposição de que nossas necessidades são necessidades corpóreas, necessidade de ação no mais baixo sentido, é seguramente injustificável. Assumir isso é degradar o homem ao nível dos brutos, negando a ele qualquer aspiração diferente daquelas dos animais inferiores (...). (STEBBING, 1914, p. 138)

Tal expressão de espanto perante o naturalismo me parece exagerada, mas compreendo que ela não é rara nem incomum entre os professores de ciências humanas. $\mathrm{O}$ espaço desse ensaio não me permite ir além e explorar os motivos por detrás desse tipo de atitude. Penso que a divergência entre minha leitura rortyana do voluntarismo e a leitura essencialista do pragmatismo da professora Stebbing talvez sejam inconciliáveis. Contudo, isso pode não ser um problema. Talvez a filosofia não precise procurar, acima de tudo, demonstrar que, dentre todas as posições sobre uma mesma questão, apenas uma é digna de ser levada a sério. A variedade também pode ser vista como um benefício tão grande quanto ou até maior do que - a síntese definitiva de diferentes pontos de vista. 


\section{Considerações Finais}

O ponto central da divergência entre Rorty e Stebing encontra-se em suas respectivas visões sobre os seres humanos e sobre a cultura. $\mathrm{Na}$ verdade, boa parte dos dilemas com os quais nos confrontamos poderiam ser explicados se conseguíssemos ser sinceros sobre a nossa tácita aprovação dos desenvolvimentos científicos - vamos a médicos, não curandeiros, tomamos pílulas em caso de doenças, não confiamos apenas em orações - e sobre nossa intuição, ou esperança, de que há algo sobre nós que não pode ser descrito em termos de partículas e interações socioculturais. Para algumas pessoas, palavras como "racionalidade" são mais do que meros adjetivos que aplicamos a certos modos de comportamento e fala. Minha explicação, explicitamente tendenciosa, para esse tipo de atitude é que crescemos e nos formamos no interior de uma complexa teia de tradições, hábitos e expectativas.

Embora boa parte desses hábitos possam mudar durante o processo de maturação intelectual, essa mudança, por sua vez, quase sempre implica a filiação a um outro conjunto de hábitos e pensamentos. Claro, isso não significa que - sendo formados por tradições diferentes - não podemos nos entender, dialogar, e por essa via estabelecer consensos e concordâncias na maioria dos assuntos; mas parece que há um conjunto de crenças nem sempre articuladas que não são negociáveis. Rorty chamava essas crenças de "vocabulário final" de uma pessoa. Um vocabulário final não pode ser refutado, pois nesse campo não existem premissas neutras, não podemos nos despir de nossas próprias convicções, mas podemos contar histórias alternativas sobre a sua formação, compará-las com a história de outros vocabulários semelhantes e as consequências de seu uso.

A conclusão do ponto de vista que tentei desenvolver consiste na afirmação de que a história dos desacertos do voluntarismo francês transmite uma importante lição: não é viável tentar conciliar os traços estetizantes e naturalistas que caracterizam nossa autoimagem nos dias atuais com a ultrapassada demanda platônica por um ponto de vista universal através da descoberta de nossa essência. Devemos seguir procurando novos modos de articular nossa identidade moral de modo romântico e pluralista - mantendo-nos fiéis ao espírito de nosso tempo - sem imaginar que essa articulação possa, de algum modo, mostrar que todas as outras articulações estão erradas. 


\section{REFERÊNCIAS BIBLIOGRÁFICAS}

BERLIN, I. Estudos Sobre a Humanidade. Tradução de Rosaura Einchenberg. São Paulo: Ed. Companhia das Letras, 2002.

JAMES, W. Pragmatismo e Outros Ensaios. Tradução de José Caetano da Silva. Rio de Janeiro: Ed. Lidador, 1967.

RORTY, R. Idealismo do Século XIX e Textualismo do Século XX em Consequências do Pragmatismo. LISBOA: Ed Instituto Piaget, 1982a.

RORTY, R. Um Mundo Bem Perdido em Consequências do Pragmatismo. LISBOA: Instituto Piaget $1982 \mathrm{~b}$.

RORTY, R. Objetivismo, Relativismo e Verdade. Tradução de Marco Antonio Casanova. Rio De Janeiro: Ed. Relume Dumará, 1997a.

RORTY, R. Pragmatismo sem Método em Relativismo Objetivismo e verdade. Rio de Janeiro: Ed Relume Dumará, 1997b.

RORTY, R. Consequências do Pragmatismo. Tradução de João Duarte. Lisboa: Ed. Instituto Piaget, 1999a.

RORTY, R. Philosophy and Social Hope. Baskerville, Peguin Books, 1999 b.

RORTY, R. Religious Faith, Intelectual Responsibility and Romance. In: R.Rorty, Philosophy and Social Hope. Baskerville: Ed Penguinbooks, 1999c.

RORTY, R. Ensaios Sobre Heidegger e Outros. Tradução de Marco Antonio Casanova. Rio De Janeiro: Ed. Relume Dumará, 2002.

RORTY, R. A Filosofia e o Espelho da Natureza. Tradução de Jorge Pires, Lisboa, Ed. Dom Quixote, 2004.

RORTY, R. Verdade e Progresso. Tradução de Denise R. Sales. São Paulo: Ed Manole, 2005.

RORTY, R. Contingência, Ironia e Solidariedade. São Paulo: Tradução de Vera Ribeiro. São Paulo Ed. Martin Fontes, 2007.

RORTY, R. Filosofia como Politica Cultural. Tradução de João Carlos Pijnappel. São Paulo, Ed. Martins Fontes, 2009.

STEBBING, S. Pragmatism and French Voluntarism : With especial reference to the notion of truth in the development of French philosophy from Maine de Biran to Professor Bergson. Cambridge: University Press, 1914. 